\title{
Absolute Change from Nadir in Organ Enlargement
}

National Cancer Institute

\section{Source}

National Cancer Institute. Absolute Change from Nadir in Organ Enlargement. NCI

Thesaurus. Code C135506.

The current org an enlargement minus the lowest organ enlargement previously recorded. 